\title{
Application of Response Surface Methodology and Central Composite Inscribed Design for Modeling and Optimization of Marble Surface Quality
}

\author{
Sümeyra Cevheroğlu Çıra, ${ }^{1}$ Ahmet Dăg, ${ }^{2}$ and Askeri Karakuş ${ }^{1}$ \\ ${ }^{1}$ Mining Engineering Department, Faculty of Engineering, Dicle University, 21280 Diyarbakır, Turkey \\ ${ }^{2}$ Mining Engineering Department, Faculty of Engineering, Çukurova University, 01330 Adana, Turkey \\ Correspondence should be addressed to Sümeyra Cevheroğlu Çıra; sumeyra@dicle.edu.tr
}

Received 18 April 2016; Revised 28 June 2016; Accepted 19 July 2016

Academic Editor: Antonio Riveiro

Copyright ( 2016 Sümeyra Cevheroğlu Çıra et al. This is an open access article distributed under the Creative Commons Attribution License, which permits unrestricted use, distribution, and reproduction in any medium, provided the original work is properly cited.

\begin{abstract}
Factors affecting the final surface quality of polished marble are not yet fully understood. Clarifying these factors for optimization of multivariate polishing process by trial and error method is difficult, time-consuming, and costly task. In this study, the empirical practices were carried out using an experimental design, specifically, a central composite inscribed (CCI) design. The factors considered in CCI design were belt speed, rotational speed, and pressure of the polishing head, and the responses were surface glossiness and roughness. Mathematical models describing responses were produced using experimental datasets, and analysis of variance (ANOVA) was used to assess the fit of the models generated with the experimental data. For process optimization, desirability function analysis (DFA) was used. This study has shown that the CCI could efficiently be applied for the modelling of polishing machine for surface quality of marble strips. Better surface quality generally resulted from lower belt speeds, which increased contact time between the abrasives and strips. Optimized surface quality for marble specimen was established.
\end{abstract}

\section{Introduction}

Since ancient times, marble has been used in artistic fields due to its strength. Today, in parallel with the development of technology and rising living standards, marble is used for many purposes, such as floorings and coatings and interior and exterior designs of buildings, and because of the fact that it satisfies environmental regulations. For decorative purposes, polished marbles are widely preferred in the global market because of their pleasing aesthetic appearance. To obtain a polished surface, polishing process is applied to the stone. This process can represent an important part $(>40 \%)$ of the total production cost [1].

Many researchers have conducted studies aimed at decreasing the cost of polishing and have investigated parameters affecting surface quality. The effects of mineralogicalpetrographical and chemical variables on the surface roughness and glossiness were investigated by Gürcan et al. [2]. The effects of mineral composition, structure, joint fillings of the stone, and the angular relationship between cutting direction and crystal orientation were investigated by Erdoğan [3]. Ribeiro et al. [4] studied the relationship between cutting speed and roughness by characterizing stones using petrographic analyses, Knoop hardness, deep abrasion, and Amsler wear. The effects of diamond and $\mathrm{SiC}$ abrasives on surface quality were investigated by Görgülü and Ceylanoğlu [5]. Huang et al. [6] studied the relationship between the morphology of the stone and surface quality from sawing to polishing by measuring roughness and glossiness values. Furthermore, Ersoy and Kose [7] investigated the relationship between polishing ease and the mechanical properties of marble. Karaca [8] studied the relationship between mechanical properties and the surface roughness of marble samples. Yavuz et al. [1] and Ersoy et al. [9] investigated the effects of belt speed on surface quality by performing polishing tests at various speeds under fixed rotational speed and pressure of the polishing head. However, few studies have investigated optimization of the marble surface. To our knowledge, this 
TABLE 1: Results of physicomechanical tests.

\begin{tabular}{lcccccr}
\hline Marble unit & UW $\left(\mathrm{KN} / \mathrm{m}^{3}\right)$ & $P(\%)$ & UCS $(\mathrm{MPa})$ & FS $(\mathrm{MPa})$ & ITS $(\mathrm{MPa})$ & $\begin{array}{c}\text { BAR } \\
\left(\mathrm{cm}^{3} / 50 \mathrm{~cm}^{2}\right)\end{array}$ \\
\hline Adara & 25.7 & 0.39 & 77.9 & 15.01 & 7.53 & 15.76 \\
Emperador & 25.8 & 1.85 & 61.69 & 13.44 & 7.23 & 18.79 \\
Crema Nera & 26.59 & 0.34 & 83.99 & 12.9 & 8.6 & 41.2 \\
Sand Wave & 27.08 & 1.46 & 72.05 & 8.96 & 7.35 & 43.6 \\
\hline
\end{tabular}

Unit weight (UW), porosity (P), uniaxial compressive strength (UCS), flexural strength (FS), indirect tensile strength (ITS), Bohme abrasion resistance (BAR), and Schmidt hardness (SH).

TABLE 2: Coded/actual levels of factors.

\begin{tabular}{|c|c|c|c|c|c|c|}
\hline \multirow{3}{*}{ Factors } & \multirow{3}{*}{ Symbol } & \multicolumn{5}{|c|}{ Coded/actual variable level } \\
\hline & & Lowest & Low & Centre & High & Highest \\
\hline & & -1.682 & -1 & 0 & 1 & 1.682 \\
\hline Belt speed $(\mathrm{m} / \mathrm{min})$ & $X_{1}$ & 0.80 & 1.07 & 1.48 & 1.88 & 2.15 \\
\hline Pressure of the polishing head (bar) & $X_{2}$ & 0.50 & 0.80 & 1.25 & 1.70 & 2 \\
\hline $\begin{array}{l}\text { Rotational speed of the polishing head } \\
(\mathrm{rpm})\end{array}$ & $X_{3}$ & 409 & 445.69 & 499.50 & 553.31 & 590 \\
\hline
\end{tabular}

TABLE 3: Experimental programme.

\begin{tabular}{|c|c|c|c|c|c|c|}
\hline \multirow[t]{2}{*}{ Test number } & \multicolumn{3}{|c|}{ Coded level of variables } & \multicolumn{3}{|c|}{$\begin{array}{l}\text { Actual level of } \\
\text { variables }\end{array}$} \\
\hline & $X_{1}$ & $X_{2}$ & $X_{3}$ & $X_{1}$ & $X_{2}$ & $X_{3}$ \\
\hline 1 & 1 & -1 & 1 & 1.88 & 0.80 & 553.31 \\
\hline 2 & 0 & 0 & 0 & 1.48 & 1.25 & 499.50 \\
\hline 3 & -1 & 1 & 1 & 1.07 & 1.70 & 553.31 \\
\hline 4 & 0 & 0 & 1.682 & 1.48 & 1.25 & 590.00 \\
\hline 5 & 0 & 0 & -1.682 & 1.48 & 1.25 & 409.00 \\
\hline 6 & 0 & 0 & 0 & 1.48 & 1.25 & 499.50 \\
\hline 7 & 1 & 1 & -1 & 1.88 & 1.70 & 445.69 \\
\hline 8 & -1 & 1 & -1 & 1.07 & 1.70 & 445.69 \\
\hline 9 & 0 & -1.682 & 0 & 1.48 & 0.50 & 499.50 \\
\hline 10 & 1 & 1 & 1 & 1.88 & 1.70 & 553.31 \\
\hline 11 & 0 & 1.682 & 0 & 1.48 & 2.00 & 499.50 \\
\hline 12 & 0 & 0 & 0 & 1.48 & 1.25 & 499.50 \\
\hline 13 & -1.682 & 0 & 0 & 0.80 & 1.25 & 499.50 \\
\hline 14 & 0 & 0 & 0 & 1.48 & 1.25 & 499.50 \\
\hline 15 & 0 & 0 & 0 & 1.48 & 1.25 & 499.50 \\
\hline 16 & -1 & -1 & -1 & 1.07 & 0.80 & 445.69 \\
\hline 17 & 1.682 & 0 & 0 & 2.15 & 1.25 & 499.50 \\
\hline 18 & 1 & -1 & -1 & 1.88 & 0.80 & 445.69 \\
\hline 19 & -1 & -1 & 1 & 1.07 & 0.80 & 553.31 \\
\hline 20 & 0 & 0 & 0 & 1.48 & 1.25 & 499.50 \\
\hline
\end{tabular}

is the first reported study to use an experimental design to optimize marble surface quality.

The main objective of this research was to determine the effects of operating variables on surface quality and to identify appropriate parameter settings that produced optimum surface quality, with maximum glossiness and minimum roughness values. However, observing the effects of polishing machine operating variables on surface quality by varying two factors at a time while keeping the others constant requires many individual tests, increasing experimental costs. Moreover, interactions between factors cannot be assessed. With the use of an experimental design, it is possible to remove the complications associated with trial and error methods.

Experimental design methodology is being divided into a few types, such as factorial, mixture, crossed, and response surface methodology (RSM). Among the other types, RSM was selected according to the purpose of this study mentioned above.

\section{Materials and Methods}

Polishing tests were conducted with a laboratory-scale polishing machine, equipped with a conveyor belt and four polishing heads, which was designed to be similar to an industrial-scale machine (Figure 1). Limestones, Adara, Emperador, Crema Nera, and Sand Wave, from Adıyaman, Kahramanmaraş, and Diyarbakir, Turkey, were used. For determining the material properties of specimen physicomechanical tests were carried out and the results were presented in Table 1. For utilizing the results of the polishing tests directly in industrial applications, $500 \mathrm{~mm}$ long and $300 \mathrm{~mm}$ wide and $20 \mathrm{~mm}$ thick industrial dimensioned specimens were selected also by considering the type of polishing machine.

Central composite design (CCD) one of the most popular RSM due to Box and Wilson [10] was selected as the experimental design method. There are three main varieties of CCD, namely, Central Composite Circumscribed (CCC), central composite inscribed (CCI), and Central Composite Faced (CCF) ones. CCC designs are the original form of the central composite design. In the CCC design the low and high values of each factor have been extended to create the star points. 
TABLE 4: ANOVA results for roughness.

\begin{tabular}{|c|c|c|c|c|c|c|}
\hline & Source & $\mathrm{df}$ & SS & MS & $F$-ratio & $P$ value \\
\hline \multirow{4}{*}{ Adara } & Model & 9 & $1.319 E-003$ & $1.466 E-004$ & 32.36 & $<0.0001$ \\
\hline & Residual & 10 & $4.530 E-005$ & $4.530 E-006$ & & \\
\hline & Total & 19 & $1.365 E-003$ & & & \\
\hline & $R^{2}=0.966$ & $R_{\text {adj }}^{2}=0.936$ & & & & \\
\hline \multirow{4}{*}{ Emperador } & Model & 9 & $1.889 E-003$ & $2.099 E-004$ & 25.11 & $<0.0001$ \\
\hline & Residual & 10 & $8.360 E-005$ & $8.360 E-006$ & & \\
\hline & Total & 19 & $1.973 E-003$ & & & \\
\hline & $R^{2}=0.957$ & $R_{\text {adj }}^{2}=0.919$ & & & & \\
\hline \multirow{4}{*}{ Crema Nera } & Model & 9 & $2.010 E-003$ & $2.233 E-004$ & 23.40 & $<0.0001$ \\
\hline & Residual & 10 & $9.542 E-005$ & $9.542 E-005$ & & \\
\hline & Total & 19 & $2.105 E-003$ & & & \\
\hline & $R^{2}=0.954$ & $R_{\text {adj }}^{2}=0.913$ & & & & \\
\hline \multirow{4}{*}{ Sand Wave } & Model & 9 & $1.000 E-003$ & $1.111 E-004$ & 30.52 & $<0.0001$ \\
\hline & Residual & 10 & $3.641 E-005$ & $3.641 E-005$ & & \\
\hline & Total & 19 & $1.037 E-003$ & & & \\
\hline & $R^{2}=0.964$ & $R_{\text {adj }}^{2}=0.933$ & & & & \\
\hline
\end{tabular}

df: degrees of freedom, SS: sum of squares, and MS: mean square.

TABLE 5: ANOVA results for glossiness.

\begin{tabular}{|c|c|c|c|c|c|c|}
\hline & Source & $\mathrm{df}$ & SS & MS & $F$-ratio & $P$ value \\
\hline \multirow{4}{*}{ Adara } & Model & 9 & 226.50 & 25.17 & 22.46 & $<0.0001$ \\
\hline & Residual & 10 & 11.21 & 1.12 & & \\
\hline & Total & 19 & 237.70 & & & \\
\hline & $R^{2}=0.952$ & $R_{\text {adj }}^{2}=0.910$ & & & & \\
\hline \multirow{4}{*}{ Emperador } & Model & 9 & 240.51 & 26.72 & 16.35 & $<0.0001$ \\
\hline & Residual & 10 & 16.34 & 1.63 & & \\
\hline & Total & 19 & 256.85 & & & \\
\hline & $R^{2}=0.936$ & $R_{\text {adj }}^{2}=0.879$ & & & & \\
\hline \multirow{4}{*}{ Crema Nera } & Model & 9 & 361.59 & 40.18 & 24.21 & $<0.0001$ \\
\hline & Residual & 10 & 16.59 & 1.66 & & \\
\hline & Total & 19 & 378.19 & & & \\
\hline & $R^{2}=0.956$ & $R_{\text {adj }}^{2}=0.916$ & & & & \\
\hline \multirow{4}{*}{ Sand Wave } & Model & 9 & 118.93 & 13.21 & 65.39 & $<0.0001$ \\
\hline & Residual & 10 & 2.02 & 0.2 & & \\
\hline & Total & 19 & 120.95 & & & \\
\hline & $R^{2}=0.983$ & $R_{\text {adj }}^{2}=0.968$ & & & & \\
\hline
\end{tabular}

df: degrees of freedom, SS: sum of squares, and MS: mean square.

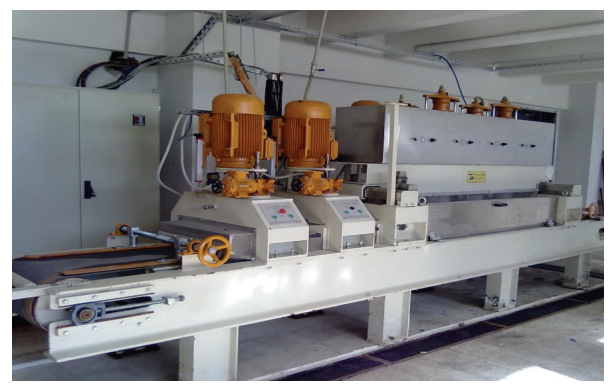

FIgURE 1: Polishing machine. 


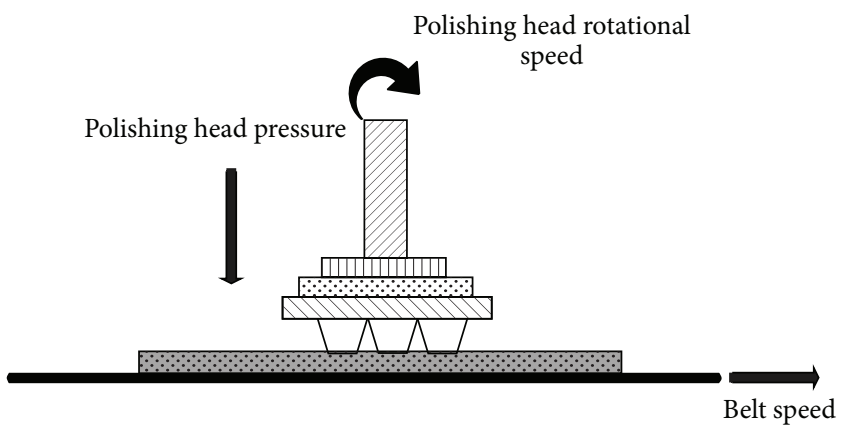

FIGURE 2: Polishing machine operating variables.



(a) Adara

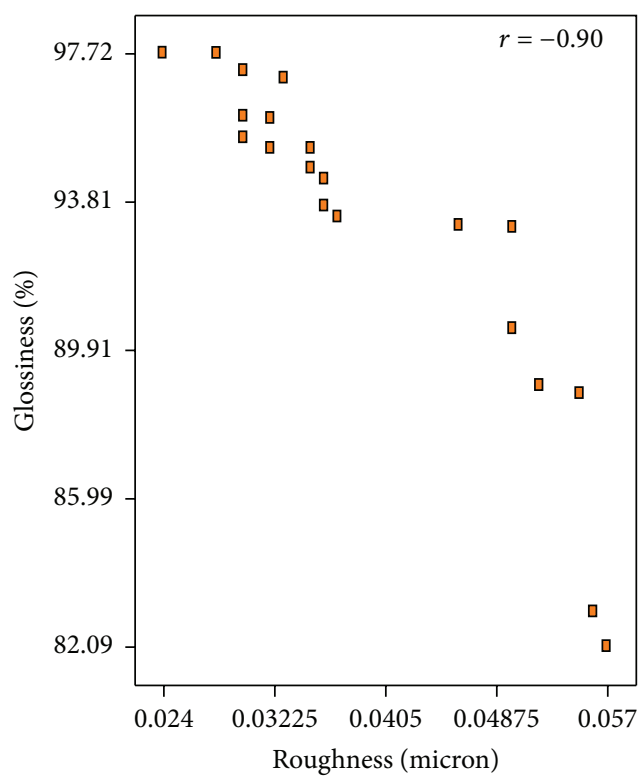

(c) Crema Nera

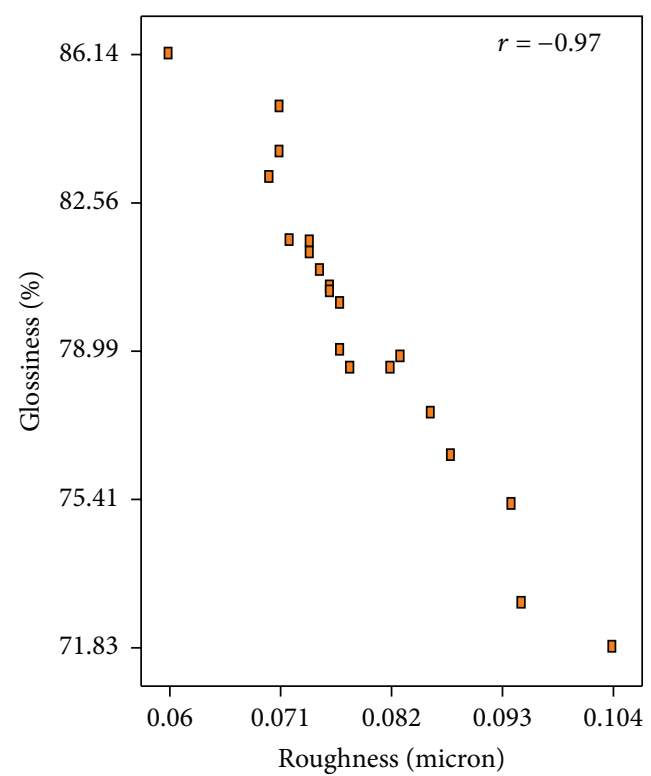

(b) Emperador

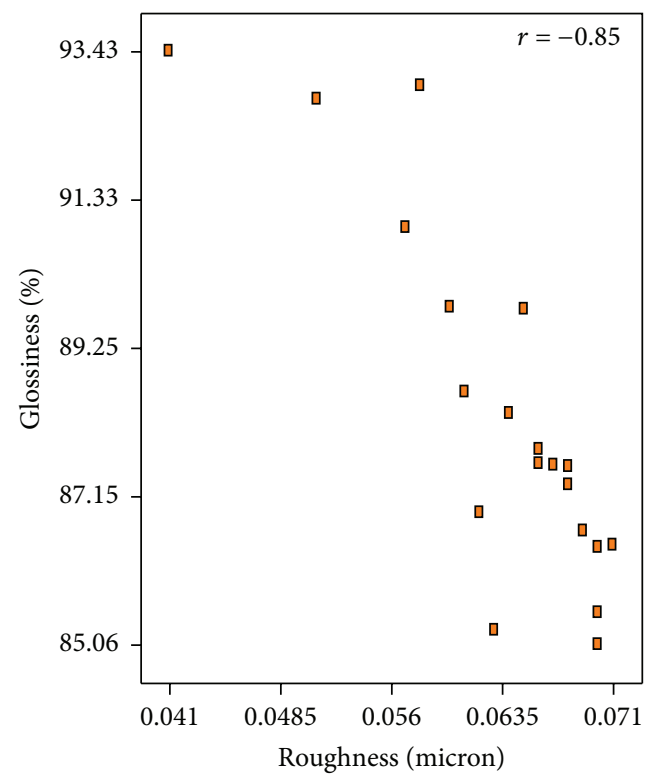

(d) Sand Wave

FIGURE 3: Relationship between glossiness and roughness. 
TABLE 6: Results of desirability function analysis.

\begin{tabular}{|c|c|c|c|c|c|c|}
\hline Specimen & $\begin{array}{c}X_{1} \\
(\mathrm{~m} / \mathrm{min})\end{array}$ & $\begin{array}{c}X_{2} \\
\text { (bar) }\end{array}$ & $\begin{array}{c}X_{3} \\
(\mathrm{rpm}) \\
\end{array}$ & Roughness $(\mu \mathrm{m})$ & Glossiness (\%) & Desirability \\
\hline \multirow{10}{*}{ Adara } & 1.43 & 1.99 & 430.24 & 0.024353 & 98.5184 & 1 \\
\hline & 1.42 & 1.91 & 456.94 & 0.026821 & 97.2577 & 1 \\
\hline & 1.27 & 1.87 & 445.78 & 0.025516 & 97.6224 & 1 \\
\hline & 1.14 & 1.91 & 472.54 & 0.026655 & 97.2 & 1 \\
\hline & 1.51 & 1.99 & 452.32 & 0.02663 & 97.6163 & 1 \\
\hline & 1.21 & 1.97 & 466.55 & 0.024925 & 98.0937 & 1 \\
\hline & 1.01 & 1.96 & 468.01 & 0.026377 & 97.2929 & 1 \\
\hline & 1.04 & 1.99 & 459.93 & 0.024636 & 98.1048 & 1 \\
\hline & 1.02 & 1.96 & 422.37 & 0.023883 & 98.4338 & 1 \\
\hline & 1.47 & 1.92 & 442.5 & 0.026544 & 97.4198 & 1 \\
\hline \multirow{10}{*}{ Emperador } & 1.47 & 1.92 & 442.5 & 0.026544 & 97.4198 & 1 \\
\hline & 1.05 & 1.97 & 495.61 & 0.057958 & 88.4581 & 1 \\
\hline & 0.87 & 1.89 & 490.91 & 0.054928 & 89.9367 & 1 \\
\hline & 1.06 & 1.91 & 490.97 & 0.058389 & 88.1515 & 1 \\
\hline & 0.88 & 1.78 & 466.37 & 0.055282 & 89.5013 & 1 \\
\hline & 0.96 & 1.96 & 413.53 & 0.057281 & 89.0539 & 1 \\
\hline & 0.93 & 1.92 & 488.02 & 0.05533 & 89.6604 & 1 \\
\hline & 1.06 & 1.72 & 464.13 & 0.059584 & 87.2984 & 1 \\
\hline & 0.99 & 1.79 & 480.66 & 0.058081 & 88.1641 & 1 \\
\hline & 1.23 & 1.96 & 460.77 & 0.059729 & 87.3387 & 1 \\
\hline \multirow{10}{*}{ Crema Nera } & 1.23 & 1.96 & 460.77 & 0.059729 & 87.3387 & 1 \\
\hline & 1.38 & 1.98 & 415.76 & 0.023521 & 98.9708 & 1 \\
\hline & 1.58 & 1.96 & 411.99 & 0.0232711 & 99.8326 & 1 \\
\hline & 1.35 & 1.93 & 421.76 & 0.0239895 & 98.7389 & 1 \\
\hline & 0.80 & 0.64 & 527.22 & 0.0244613 & 99.4344 & 0.992986 \\
\hline & 0.80 & 0.65 & 527.65 & 0.0244622 & 99.4177 & 0.992972 \\
\hline & 0.80 & 0.69 & 522.79 & 0.0244713 & 99.3755 & 0.992833 \\
\hline & 0.80 & 0.65 & 526.67 & 0.0244786 & 99.4078 & 0.992722 \\
\hline & 0.80 & 0.77 & 514.46 & 0.0245365 & 99.2266 & 0.991838 \\
\hline & 0.80 & 0.78 & 504.88 & 0.024713 & 99.2337 & 0.989137 \\
\hline \multirow{9}{*}{ Sand Wave } & 1.32 & 1.87 & 412.14 & 0.03903 & 95.0687 & 1 \\
\hline & 0.82 & 1.03 & 421.2 & 0.039582 & 96.1216 & 1 \\
\hline & 0.81 & 1.28 & 442.96 & 0.039169 & 95.3551 & 1 \\
\hline & 0.81 & 1.33 & 451.25 & 0.040047 & 94.903 & 1 \\
\hline & 0.88 & 1.9 & 445.67 & 0.028955 & 94.997 & 1 \\
\hline & 1.31 & 1.95 & 413.04 & 0.036807 & 95.1173 & 1 \\
\hline & 0.8 & 0.5 & 589.77 & 0.052103 & 94.5075 & 0.793667 \\
\hline & 0.8 & 0.5 & 588.93 & 0.052274 & 94.4029 & 0.790065 \\
\hline & 0.8 & 1.42 & 590 & 0.054404 & 93.43 & 0.74378 \\
\hline
\end{tabular}

The star points are at some distance " $\alpha$ " from the center based on the properties desired for the design and the number of factors in the design. In this manner the star points establish new extremes for the low and high settings for all factors. In the CCI design, the specified low and high values become the star points, and the system computes appropriate settings for the factorial part of the design inside those boundaries. CCF designs do not require using points outside the original factor range. However, they give poor precision for estimating pure quadratic coefficients [11]. In this research, only the points within the factor ranges originally specified were required. Thus CCI design was selected for determining the 


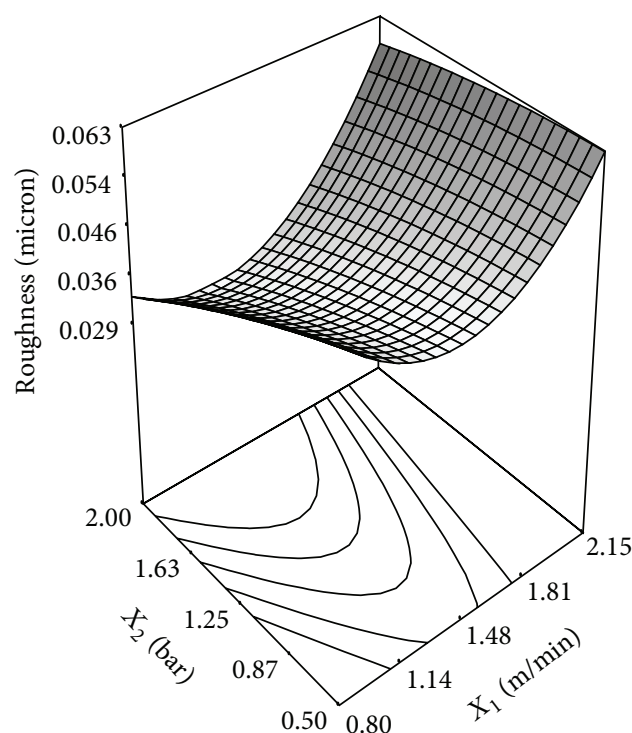

(a) Adara

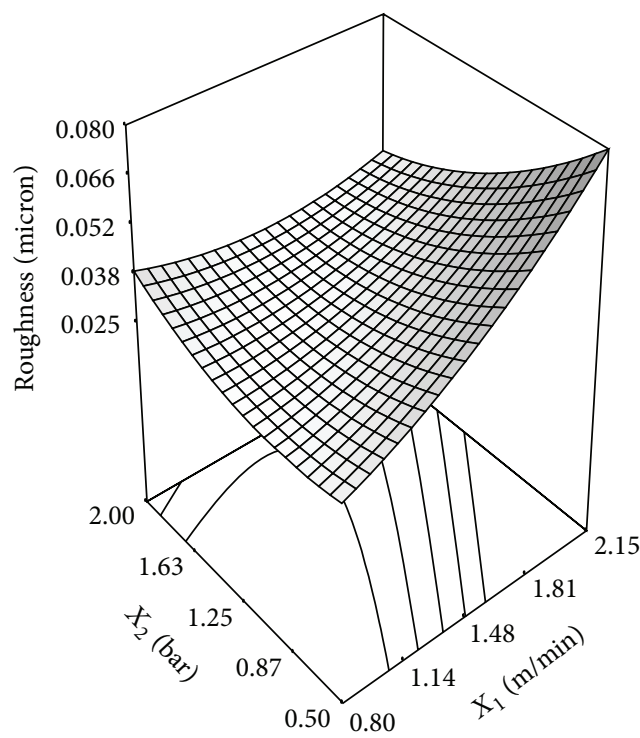

(c) Crema Nera

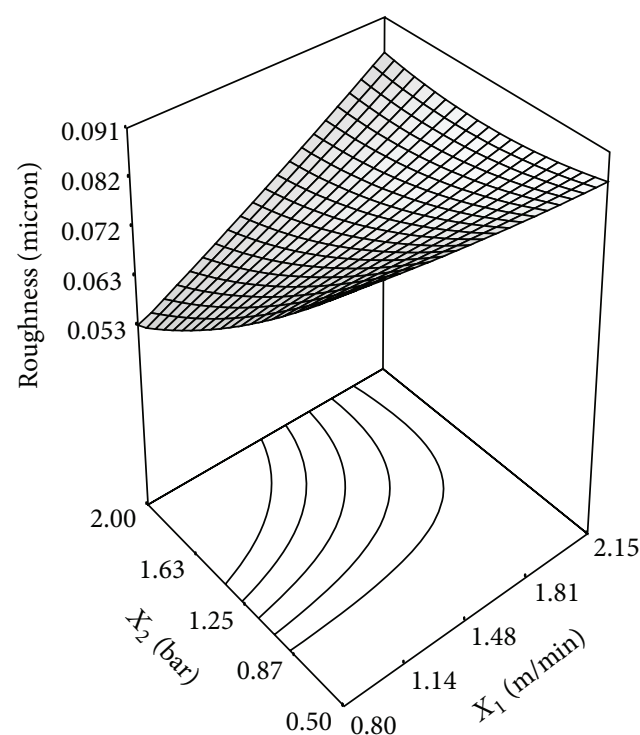

(b) Emperador

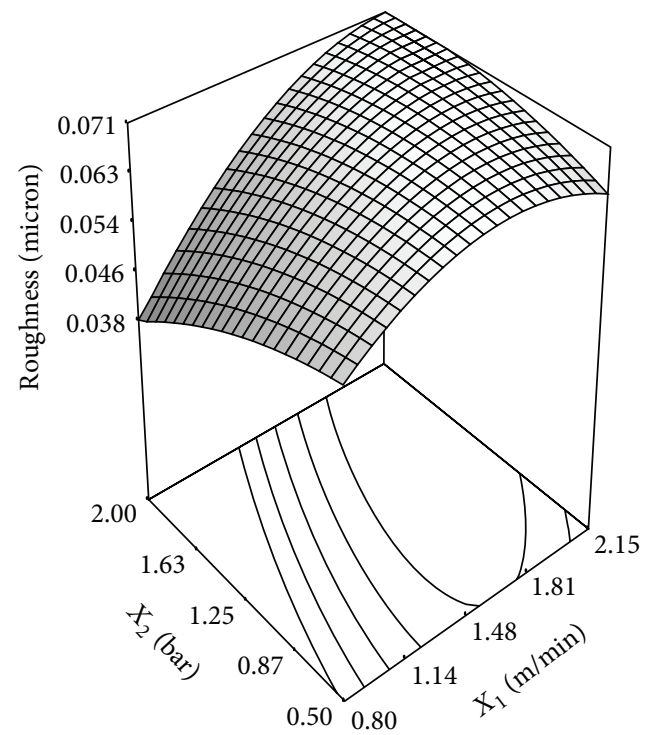

(d) Sand Wave

FIGURE 4: 3D surface plots for variations in roughness at different polishing head pressures $\left(X_{2}\right)$ and belt speeds $\left(X_{1}\right)$ at constant (499.5 rpm) polishing head rotational speed $\left(X_{3}\right)$.

experimental program and deriving mathematical equations between factors and responses to clarify the effects of operating variables of polishing machine on marble surface quality.

Three operating polishing machine variables, that is, belt speed $\left(X_{1}\right)$, polishing head pressure $\left(X_{2}\right)$, and polishing head rotational speed $\left(X_{3}\right)$, were assessed as factors, and surface glossiness and roughness were selected as responses in the CCI design. The experimental studies started by identifying the ranges of these factors, which are shown in Figure 2. Using the Design-Expert 6.0 software (trial), actual levels of factors (Table 2) were determined, and an experimental programme was developed (Table 3). Belt speed, rotational speed, and pressure of the polishing head were adjusted according to the experimental programme, and 20 polishing tests were conducted for each marble type.
The abrasive series was $60,80,120,180,220,280,320$, 380, 600, 800, 5-extra, and a felt pad. The final surface quality of the strips was assessed after the felt pad was used for each of the 20 tests. For measuring average surface roughness of the strips a Taylor Hobson Surtronic 3+ portable surface roughness tester was used. A traverse length of $25 \mathrm{~mm}$ with the standard $0.8 \mathrm{~mm}$ cutoff was chosen. Ten points were marked on the edges of the strips because of the limited measuring distance of the surface roughness tester and to ensure the measurements were taken from the same points after each polishing test. The roughness values were measured in terms of the most commonly used parameter " $R_{a}$." For glossiness parameters Konica Minolta Multi Gloss 268 Gloss Meter which has a measurement range of 0-100 gloss units was chosen and the glossiness values were evaluated using 




(a) Adara

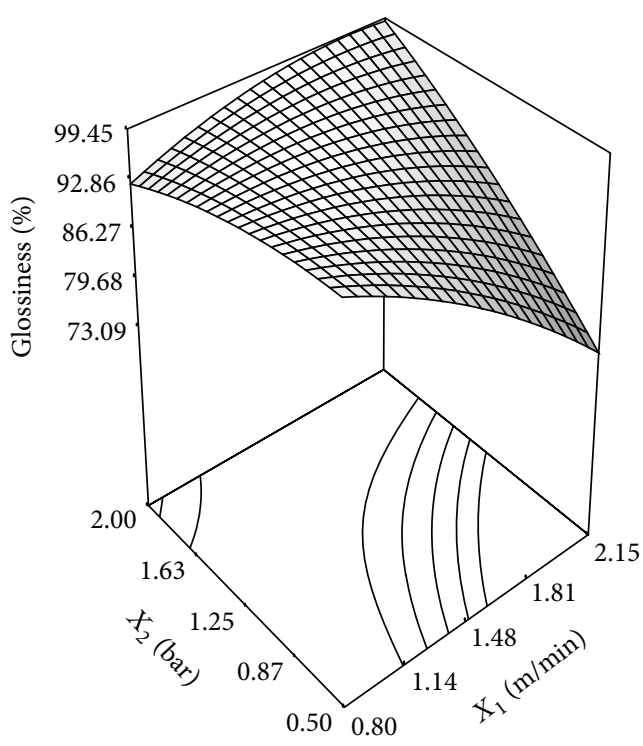

(c) Crema Nera

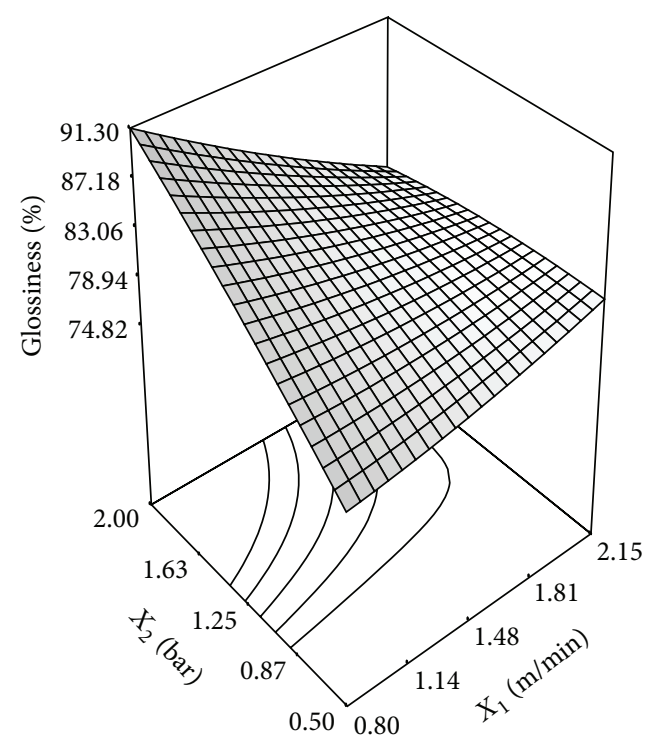

(b) Emperador

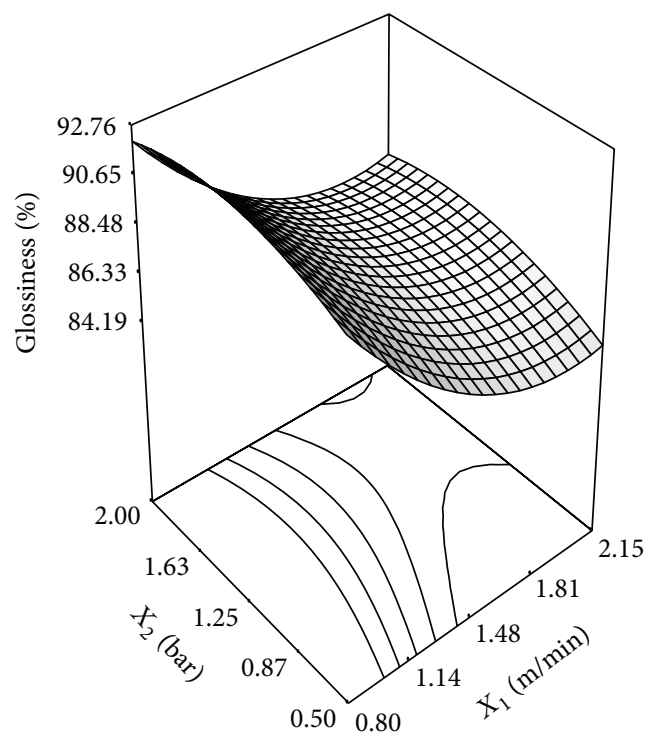

(d) Sand Wave

FIGURE 5: 3D surface plots for variations in glossiness at different polishing head pressures $\left(X_{2}\right)$ and belt speeds $\left(X_{1}\right)$ at constant (499.5 rpm) polishing head rotational speed $\left(X_{3}\right)$.

a $60^{\circ}$ angle and a $9 \times 15 \mathrm{~mm}$ area. The arithmetic means of 10 measurements were calculated, and surface profiles of the strips were determined.

At the end of 20 polishing tests, regression models were developed based on the experimental data. Analysis of variance (ANOVA) was used for graphical analysis of the data. Interactions between the factors and responses were analyzed. The goodness of fit of the polynomial model was expressed by the coefficient of determination $\left(R^{2}\right)$, and its statistical significance was checked using the Fisher $F$-test. Three-dimensional (3D) plots were obtained based on the effects of the levels of two factors. Also distribution plots were drawn in order to reveal the relationship between glossiness and roughness of the specimen.

\section{Results and Discussion}

3.1. Development and Evaluation of Response Models. Quadratic equations (1)-(8) representing the relationships between responses and factors were developed for the coded factors ((1)-(2) for Adara, (3)-(4) for Emperador, (5)-(6) for Crema Nera, and (7)-(8) for Sand Wave units). In these equations, roughness $\left(r_{1}-r_{4}\right)$ and glossiness $\left(g_{1}-g_{4}\right)$ were determined as functions of the factors. Belt speed, pressure, and rotational speed of the polishing head are shown as $X_{1}$, $X_{2}$, and $X_{3}$, respectively (Table 1 ). Consider

$$
\begin{aligned}
r_{1}= & +0.039+4.683 e-003 X_{1}-3.944 e-003 X_{2} \\
& +4.014 e-003 X_{3}+5.281 e-003 X_{1}^{2}
\end{aligned}
$$




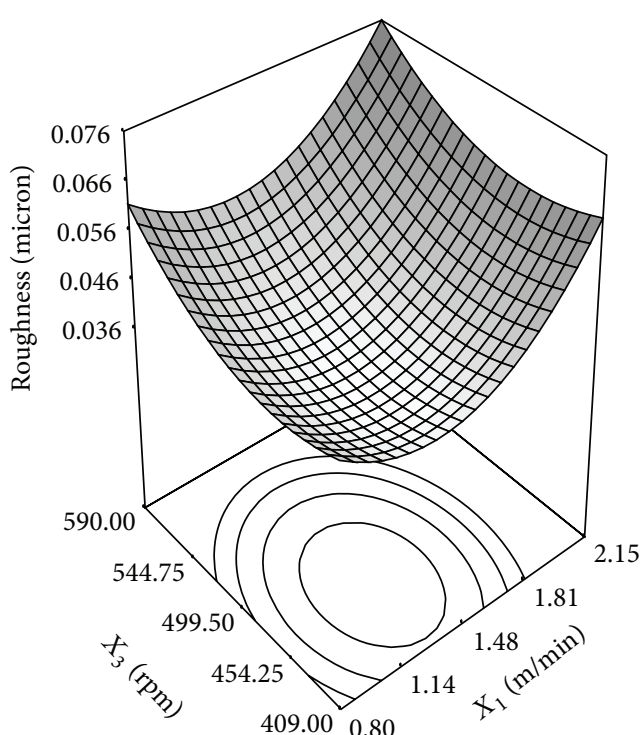

(a) Adara

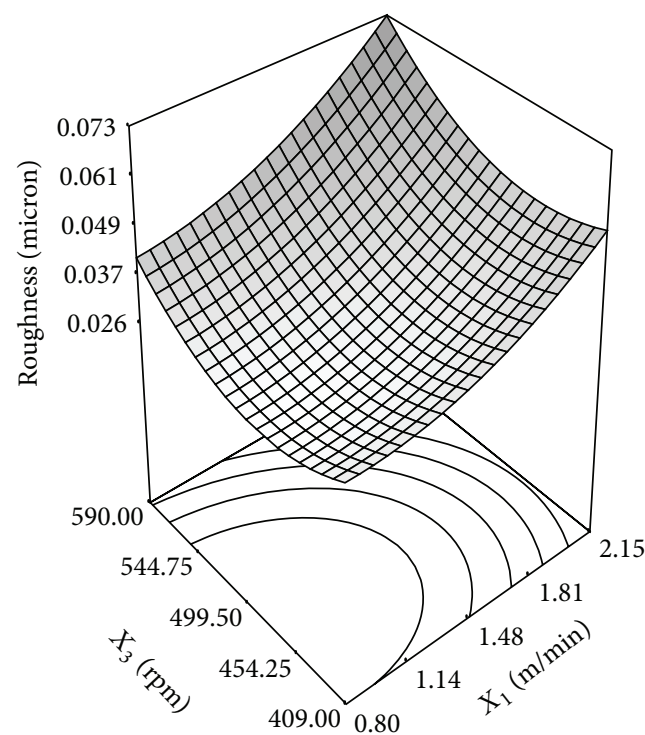

(c) Crema Nera

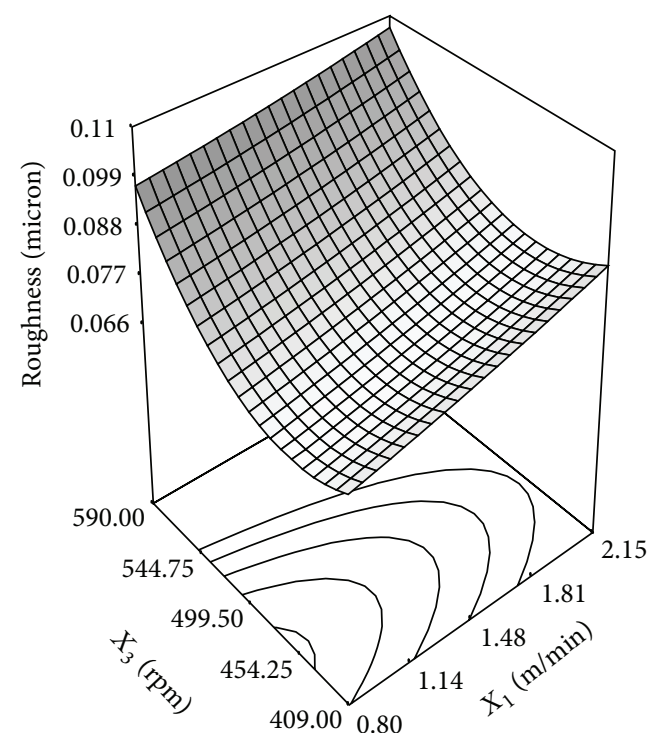

(b) Emperador

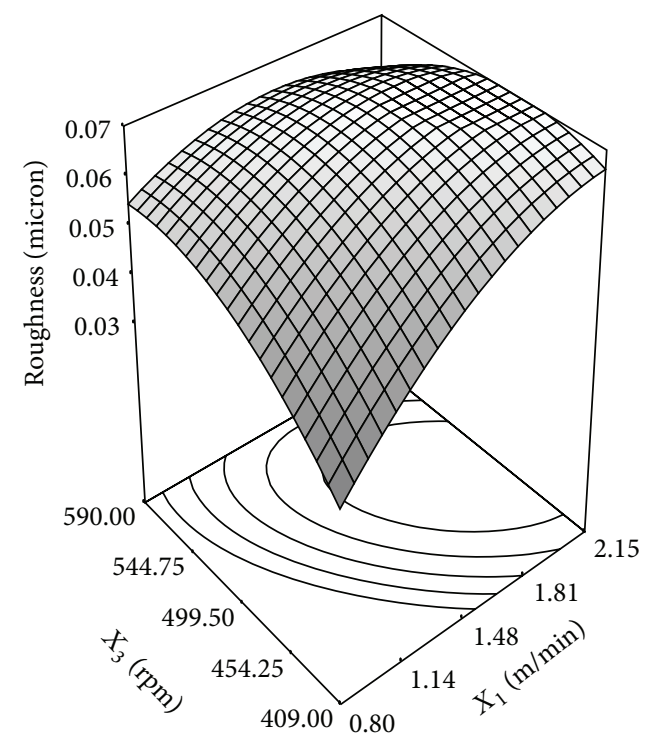

(d) Sand Wave

FIGURE 6: 3D surface plots for variations in roughness at different polishing head rotational speeds $\left(X_{3}\right)$ and belt speeds $\left(X_{1}\right)$ at constant $(1.25$ bar) polishing head pressure $\left(X_{2}\right)$.

$$
\begin{aligned}
& -3.763 e-004 X_{2}^{2}+2.982 e-003 X_{3}^{2} \\
& +1.500 e-003 X_{1} X_{2}-2.500 e-004 X_{1} X_{3} \\
& +2.750 e-003 X_{2} X_{3}, \\
g_{1}= & +91.52-2.10 X_{1}+1.88 X_{2}-1.14 X_{3}-2.26 X_{1}^{2} \\
& +0.50 X_{2}^{2}-0.92 X_{3}^{2}-0.33 X_{1} X_{2} \\
& +0.20 X_{1} X_{3}-1.06 X_{2} X_{3},
\end{aligned}
$$

$$
\begin{aligned}
r_{2}= & +0.075+3.844 e-003 X_{1}-5.948 e-003 X_{2} \\
& +7.402 e-003 X_{3}+2.556 e-004 X_{1}{ }^{2} \\
& +9.627 e-004 X_{2}{ }^{2}+5.029 e-003 X_{3}{ }^{2} \\
& +3.250 e-003 X_{1} X_{2}-5.000 e-004 X_{1} X_{3} \\
& -2.500 e-004 X_{2} X_{3}, \\
g_{2}= & +80.88-1.31 X_{1}+2.24 X_{2}-2.43 X_{3}+0.19 X_{1}{ }^{2} \\
& -0.20 X_{2}{ }^{2}-1.77 X_{3}{ }^{2}-1.58 X_{1} X_{2} \\
& +0.22 X_{1} X_{3}-0.020 X_{2} X_{3},
\end{aligned}
$$




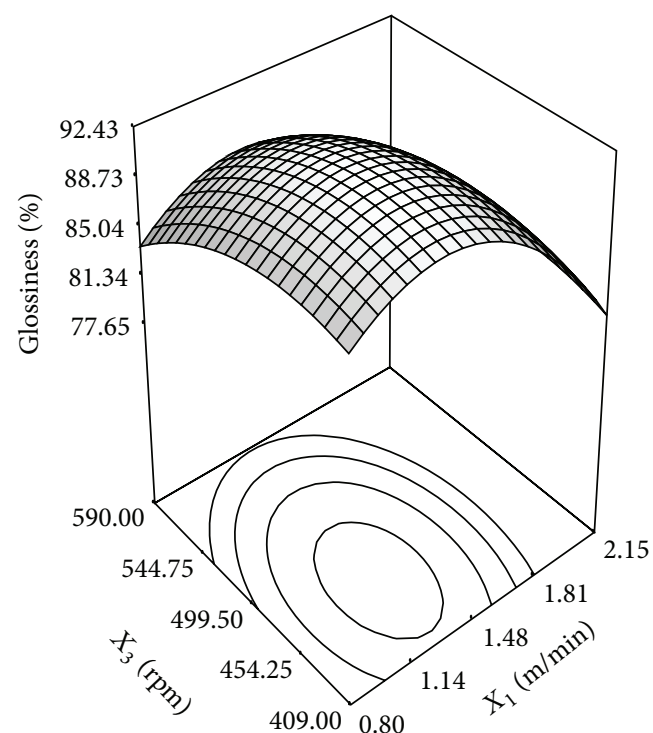

(a) Adara

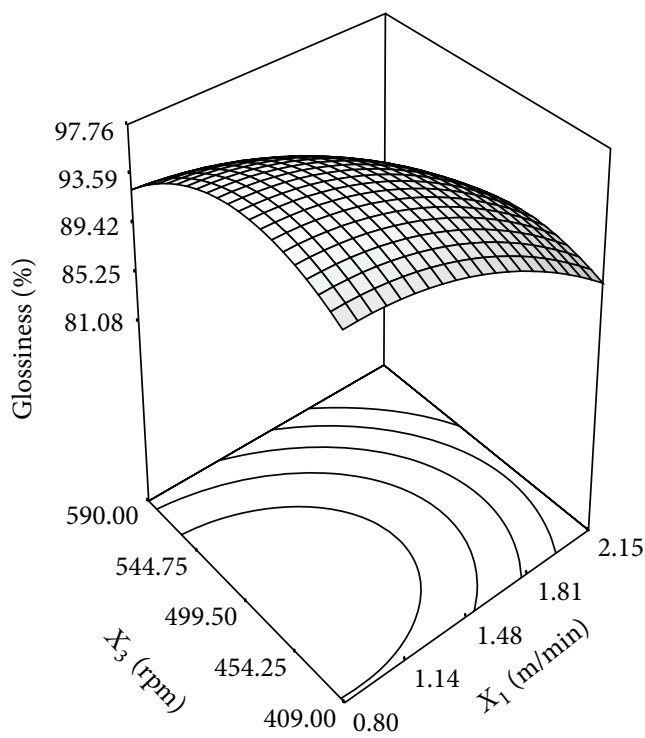

(c) Crema Nera

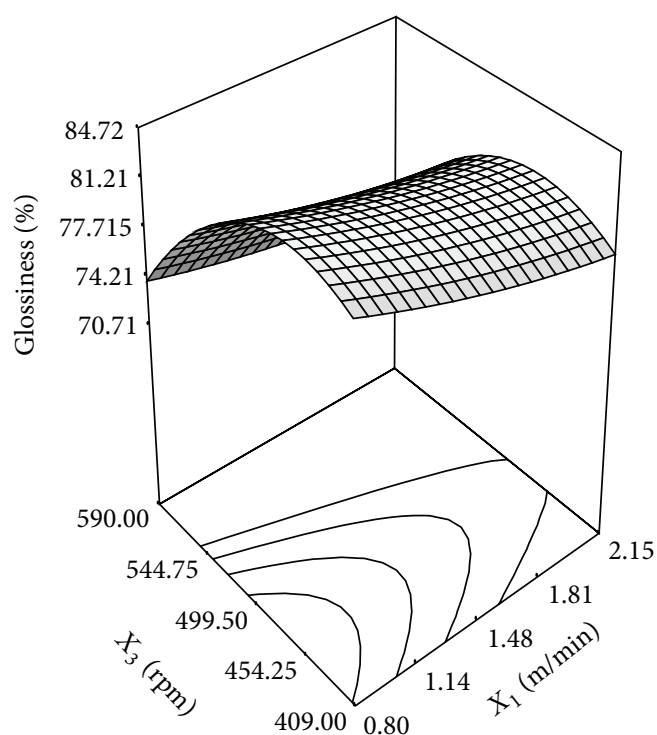

(b) Emperador

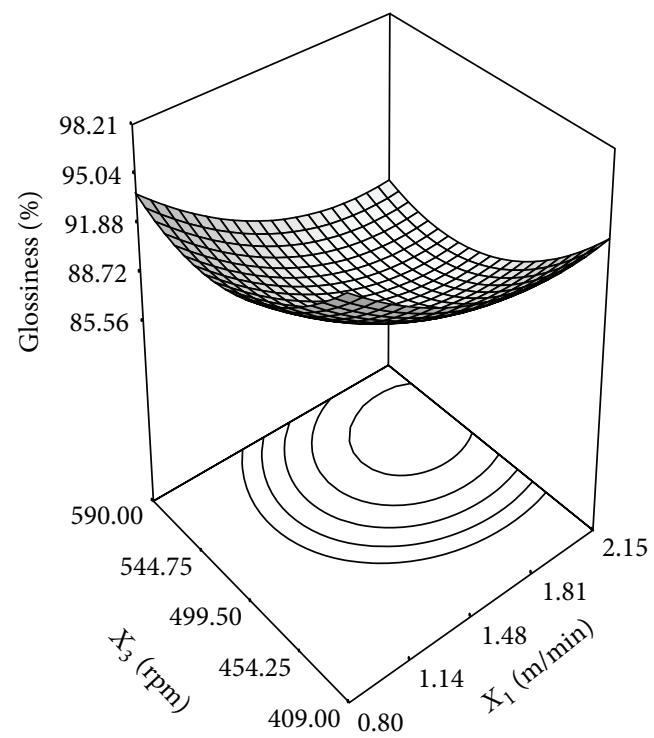

(d) Sand Wave

FIGURE 7: 3D surface plots for variations in glossiness at different polishing head rotational speeds $\left(X_{3}\right)$ and belt speeds $\left(X_{1}\right)$ at constant $(1.25$ bar) polishing head pressure $\left(X_{2}\right)$.

$$
\begin{aligned}
r_{3}= & +0.033+7.918 e-003 X_{1}-4.074 e-003 X_{2} \\
& +4.167 e-003 X_{3}+2.199 e-003 X_{1}^{2} \\
& +2.376 e-003 X_{2}^{2}+3.790 e-003 X_{3}^{2} \\
& -4.750 e-003 X_{1} X_{2}+7.500 e-004 X_{1} X_{3} \\
& +5.000 e-003 X_{2} X_{3}, \\
g_{3}= & +95.12-2.92 X_{1}+2.80 X_{2}-1.22 X_{3}-0.84 X_{1}{ }^{2} \\
& -0.62 X_{2}{ }^{2}-1.39 X_{3}{ }^{2}+2.92 X_{1} X_{2} \\
& -0.26 X_{1} X_{3}-1.17 X_{2} X_{3},
\end{aligned}
$$

$$
\begin{aligned}
r_{4}= & +0.068+5.904 e-003 X_{1}-1.791 e-003 X_{2} \\
& +2.423 e-003 X_{3}-2.724 e-003 X_{1}^{2} \\
& -9.561 e-004 X_{2}^{2}-2.724 e-003 X_{3}^{2} \\
& +2.375 e-003 X_{1} X_{2}-2.875 e-003 X_{1} X_{3} \\
& +3.375 e-003 X_{2} X_{3}, \\
g_{4}= & +87.24-1.88 X_{1}+0.42 X_{2}-1.52 X_{3}+0.82 X_{1}{ }^{2} \\
& -0.38 X_{2}{ }^{2}+1.18 X_{3}{ }^{2}+0.091 X_{1} X_{2} \\
& -0.14 X_{1} X_{3}-0.76 X_{2} X_{3} .
\end{aligned}
$$




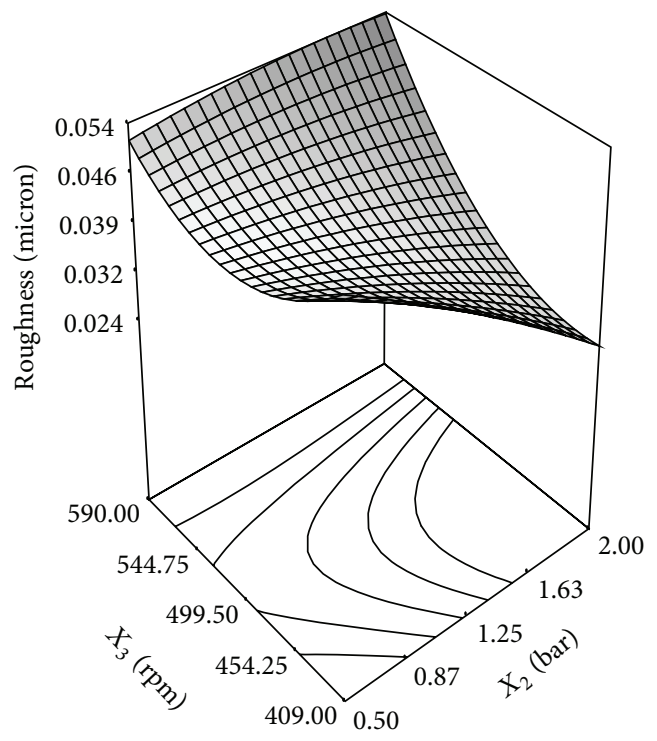

(a) Adara

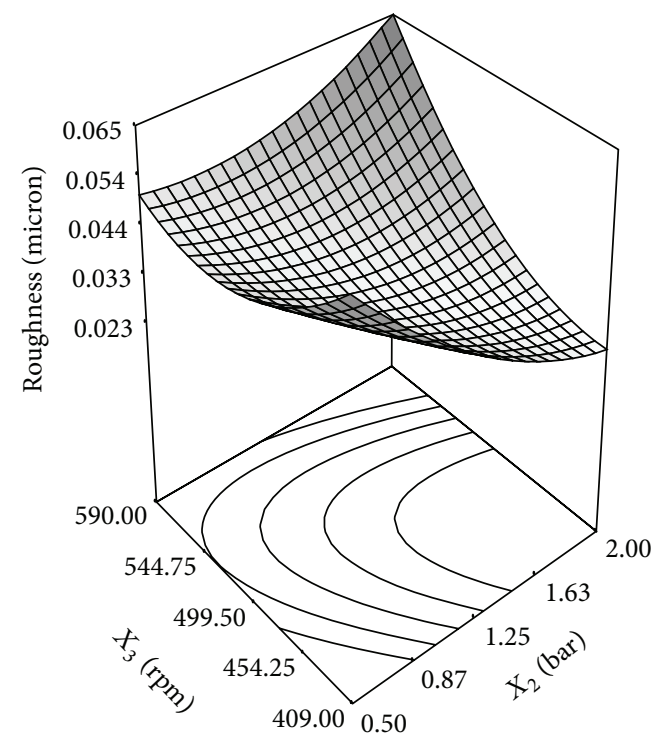

(c) Crema Nera

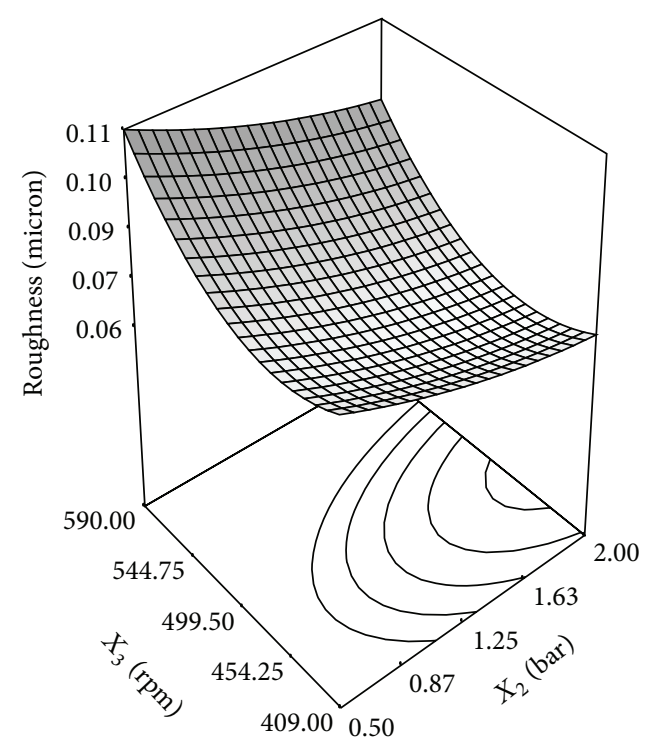

(b) Emperador

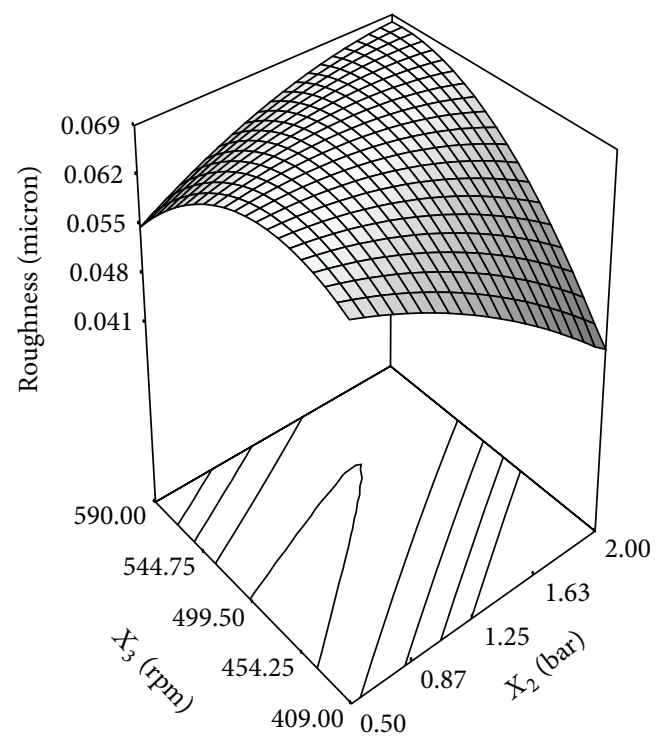

(d) Sand Wave

Figure 8: 3D surface plots for variations in roughness at different polishing head rotational speeds $\left(X_{3}\right)$ and pressures $\left(X_{2}\right)$ at constant $(1.48 \mathrm{~m} / \mathrm{min})$ belt speed $\left(X_{1}\right)$.

The results obtained from these equations were analyzed and Figure 3 was drawn to identify the relation between the responses. Figure 3 illustrates that roughness is well correlated with glossiness. The validity of the models was tested using analysis of variance (ANOVA; Tables 4 and 5). In the ANOVA test, the $F$-ratio values obtained for roughness and glossiness were higher than the tabulated $F$-value $F_{0.05}$ (9, $10=3.02$ ). Thus, it can be concluded that the models were well fitted to the data. Also, an acceptable agreement with the adjusted determination coefficient is required. In this study, the values of $R^{2}$ and $\operatorname{Adj}-R^{2}$ (Tables 4 and 5) are close to 1.0 , which is very high and advocates a high trend between the experimental and the predicted values. This indicates that the regression models provide an excellent definition of the relationship between the factors and the responses.

After the suitability of the models was confirmed, we next sought the effects of various factors on the responses. The factor with the greatest effect on the responses was detected by analyzing the coefficients of $X_{1}, X_{2}$, and $X_{3}$ from (1)(8). Belt speed (meaning contact time between abrasives and strips) clearly had the greatest effect on glossiness and roughness for Adara, Crema Nera, and Sand Wave, but the results for Emperador differed. It can be seen from equations $r_{2}$ and $g_{2}$ that the rotational speed of the polishing head (meaning the quantity of contact between abrasive and strip) had the most significant effect for Emperador. This difference 


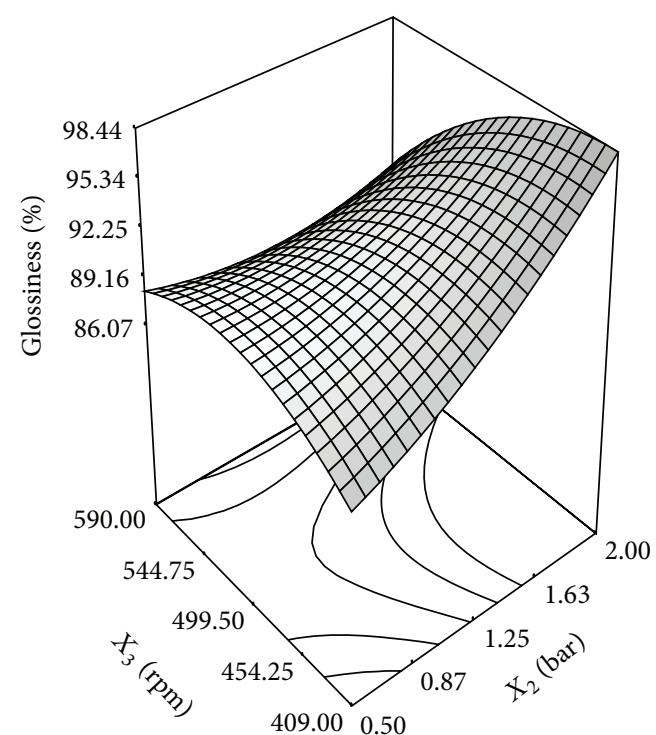

(a) Adara

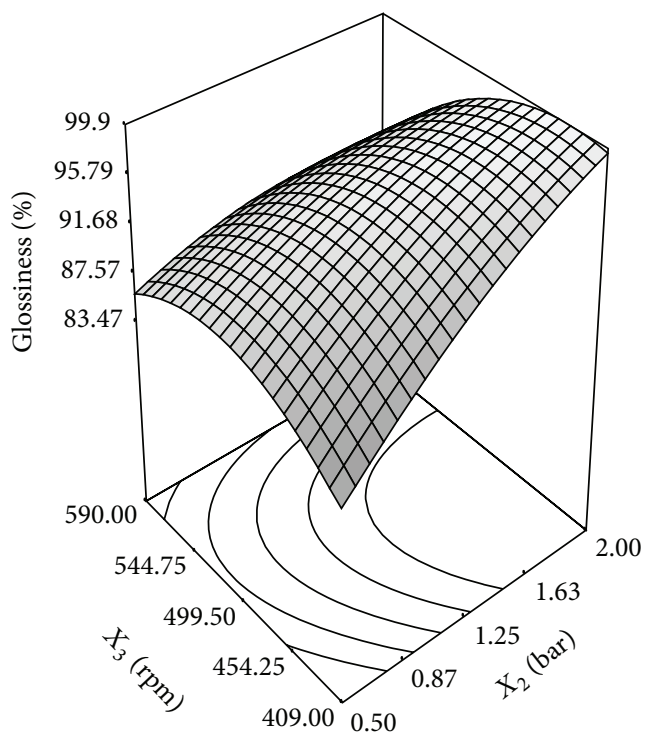

(c) Crema Nera



(b) Emperador

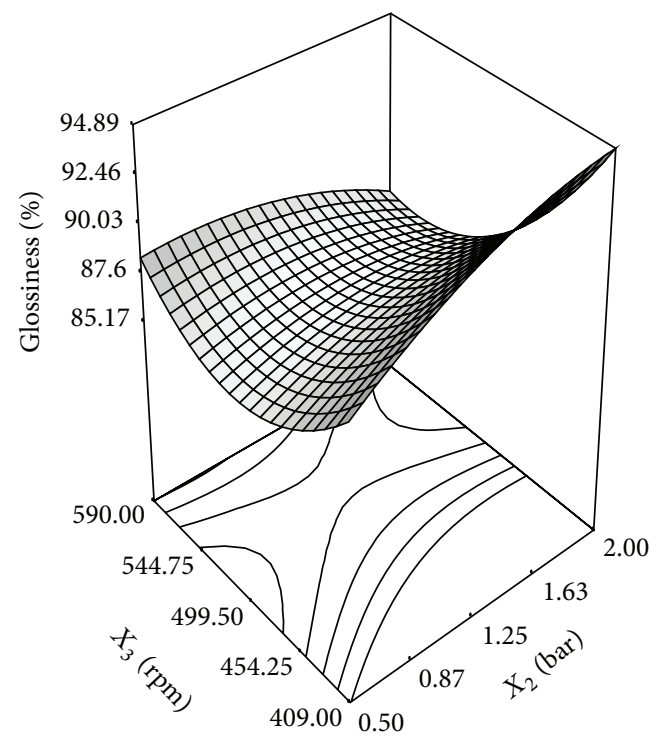

(d) Sand Wave

FIgURE 9: 3D surface plots for variations in glossiness at different polishing head rotational speed $\left(X_{3}\right)$ and pressure $\left(X_{2}\right)$ at constant $(1.48 \mathrm{~m} / \mathrm{min})$ belt speed $\left(X_{1}\right)$.

is thought to be due to Emperador's greater initial surface roughness compared with the others. Additionally, to gain a better understanding of the effects of the factors on surface quality responses, 3D response surface plots (Figures 4-9) were prepared by keeping one factor stable while varying the other two.

3D surface plots for variations in glossiness and roughness at different polishing head pressures and belt speeds at constant polishing head rotational speed are shown in Figures 4 and 5. Minimum roughness and maximum glossiness values were obtained at 2 bar polishing head pressure for Adara, Emperador, and Sand Wave, but the optimal belt speed was $1.23 \mathrm{~m} / \mathrm{min}$ for Adara (Figures 4(a) and 5(a)) and $0.8 \mathrm{~m} / \mathrm{min}$ for both Emperador (Figures 4(b) and 5(b)) and
Sand Wave (Figures 4(d) and 5(d)). For Crema Nera, the lowest roughness and highest glossiness values were achieved at $0.8 \mathrm{~m} / \mathrm{min}$ belt speed and 0.65 bar polishing head pressure (Figures 4(c) and 5(c)).

The effects of belt speed and polishing head rotational speed on roughness and glossiness at the central level of polishing head pressure are shown in Figures 6 and 7. At $1.27 \mathrm{~m} / \mathrm{min}$ and $462.73 \mathrm{rpm}$, Adara showed maximum glossiness and minimum roughness values (Figures 6(a) and 7(a)). For Emperador, Crema Nera, and Sand Wave, the highest glossiness and lowest roughness values were achieved with $0.8 \mathrm{~m} / \mathrm{min}$ belt speed and 457.87 (Figures $6(\mathrm{~b})$ and $7(\mathrm{~b})$ ), 436.64 (Figures 6(c) and 7(c)), and 409 (Figures 6(d) and $7(\mathrm{~d})) \mathrm{rpm}$ polishing head rotational speed, respectively. 


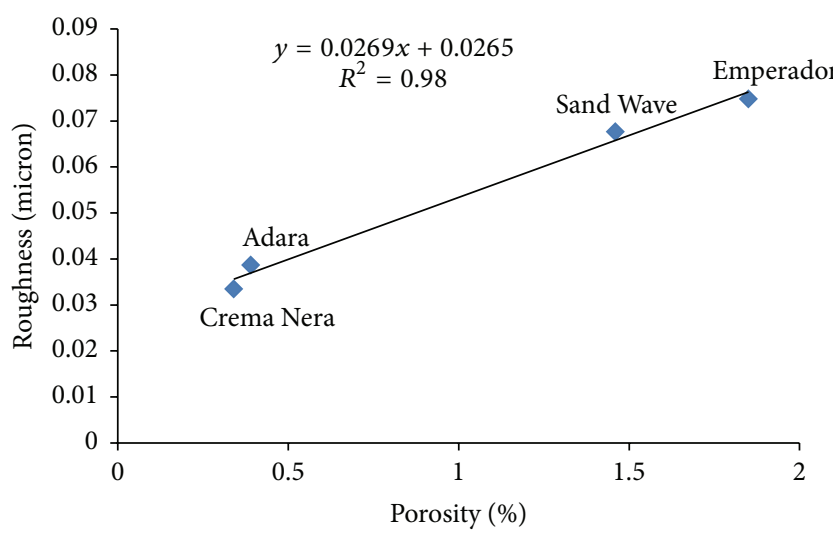

(a)

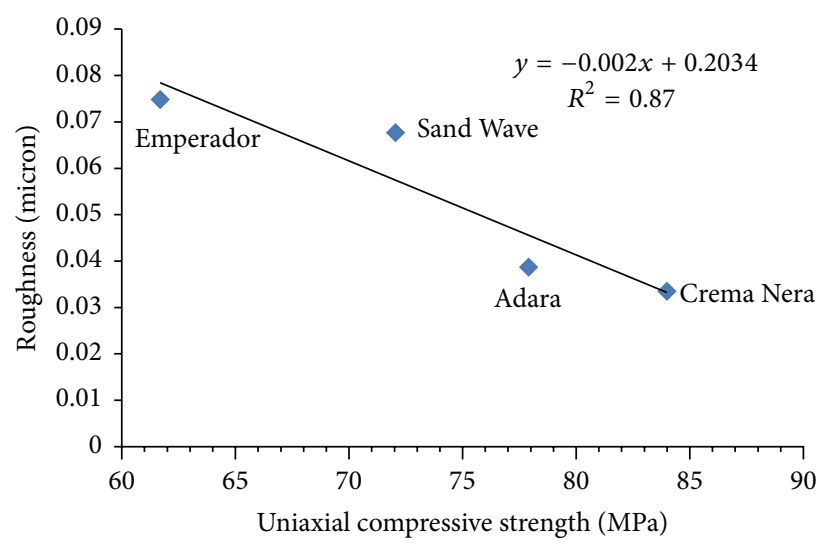

(c)

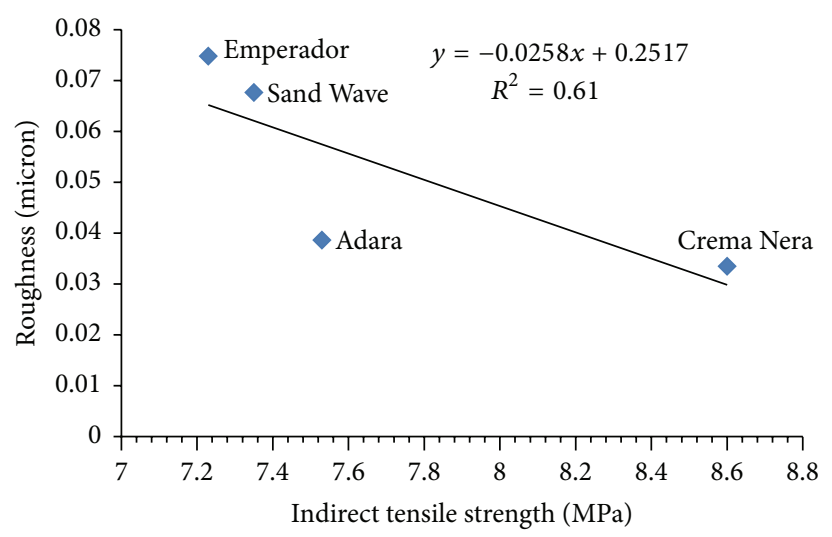

(e)

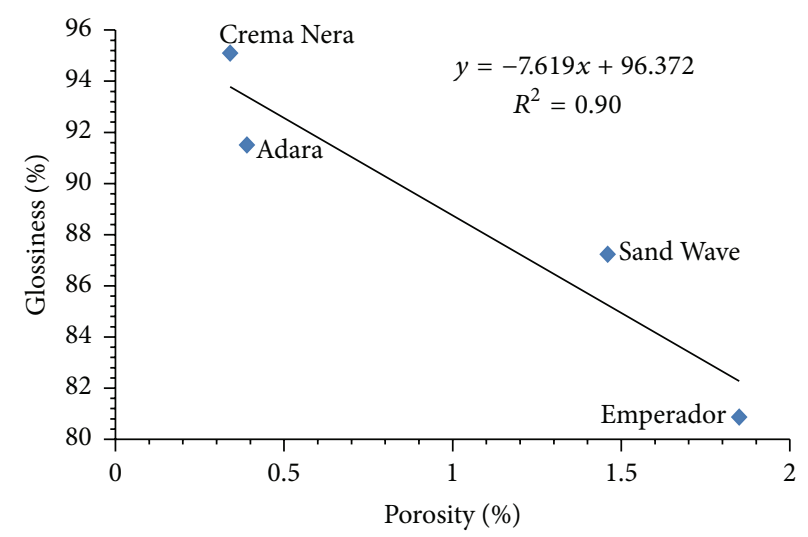

(b)

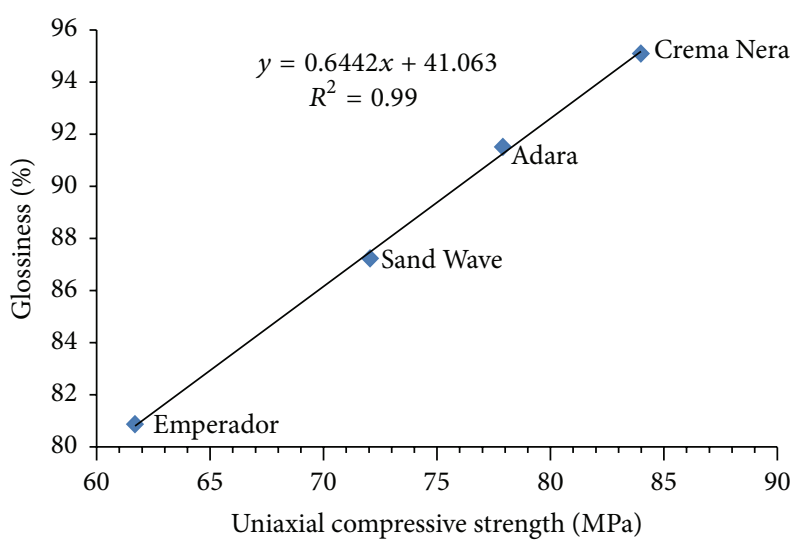

(d)



(f)

FIGURE 10: Physicomechanical properties versus roughness and glossiness.

The effects of polishing head rotational speed and pressure on glossiness and roughness at the central level of belt speed can be seen in Figures 8 and 9. To obtain the glossiest and smoothest surface, the pressure of the polishing head should be adjusted to a pressure of 2 bar and a rotational speed of 409 (Figures 8(a) and 9(a)), 461.62 (Figures 8(b) and 9(b)), 436.64 (Figures 8(c) and 9(c)), and 409 (Figures 8(d) and $9(\mathrm{~d})) \mathrm{rpm}$ for Adara, Emperador, Crema Nera, and Sand Wave, respectively.

Finally the DFA was used for the optimization of the process. Roughness values were minimized and glossiness values were maximized, in order to produce products of desired characteristics. Using the desirability function, roughness and glossiness were combined in one overall response. The results were presented in Table 6 for each marble specimen.

3.2. Effects of Physicomechanical Properties of Specimen on Surface Quality. To examine the effects of each physicomechanical property on average surface roughness and glossiness values at $1.48 \mathrm{~m} / \mathrm{min}$ belt speed, 1.25 bar pressure, and $499.5 \mathrm{rpm}$ rotational speed of the polishing head regression analysis was conducted. A linear trend $(r \geq 0.95)$ 
was observed between porosity and surface quality. By the increase of porosity roughness also increased but glossiness decreased (Figures 10(a) and 10(b)). There was an inverse linear relation between UCS and ITS and roughness (Figures 10(c)-10(e)), but it was vice versa for glossiness (Figures 10(d)-10(f)). The trend coefficients between the UW, BAR, $\mathrm{FS}$, and $\mathrm{SH}$ test results and polishing test results were lower than $48 \%$ and these values were not enough to claim existence of any relationship.

\section{Conclusions}

The RSM was shown to be useful for the design of experiments investigating the effects of the three evaluated factors (belt speed, pressure, and rotational speed of the polishing head) on the response parameters (glossiness and roughness). Experimental studies were designed according to the CCI design technique. A quadratic model was found to best fit the experimental data. The models were significant at a $95 \%$ confidence level. The factor having the greatest effect on surface quality, as determined by analyzing the coefficients of all factors in the models, was found to be belt speed, that is, contact time between the abrasives and strips, for Adara, Crema Nera, and Sand Wave. However, for Emperador, it was the rotational speed of the polishing head, that is, the quantity of contact between the abrasive and the marble strip. It can be seen from the statistical evaluations that surface quality was affected strongly by porosity and UCS.

This study was performed with a small number of marble types. To enhance the reliability of the results, different types and larger numbers of marbles should be studied.

\section{Competing Interests}

The authors declare that they have no competing interests.

\section{References}

[1] H. Yavuz, T. Özkahraman, and S. Demirdağ, "Polishing experiments on surface quality of building stone tiles," Construction and Building Materials, vol. 25, no. 4, pp. 1707-1711, 2011.

[2] S. Gürcan, R. M. Goktan, and A. Yıldız, "Effect of mineralogical and microstructural properties on surface roughness and gloss of some ornamental marbles subjected to polishing process," $X$ Ray Spectrometry, vol. 43, no. 2, pp. 70-78, 2014.

[3] M. Erdoğan, "Measurement of polished rock surface brightness by image analysis method," Engineering Geology, vol. 57, pp. 6572, 2000.

[4] R. P. Ribeiro, A. B. Paraguassú, and J. E. Rodrigues, "Sawing of blocks of siliceous dimension stone: influence of texture and mineralogy," Bulletin of Engineering Geology and the Environment, vol. 66, no. 1, pp. 101-107, 2007.

[5] K. Görgülü and A. Ceylanoğlu, "Evaluation of continuous grinding tests on some marble and limestone units with silicon carbide and diamond type abrasives," Journal of Materials Processing Technology, vol. 204, no. 1-3, pp. 264-268, 2008.

[6] H. Huang, Y. Li, J. Y. Shen, H. M. Zhu, and X. P. Xu, "Microstructure detection of a glossy granite surface machined by the grinding process," Journal of Materials Processing Technology, vol. 129, no. 1-3, pp. 403-407, 2002.
[7] M. Ersoy and H. Kose, "The relationship between easiness to polishing and mechanical properties of marbles," in Proceedings of the National Marble Symposium, pp. 337-349, Afyon, Turkey, 2001, http://www.maden.org.tr/resimler/ekler/ e4243f5511fd6ef_ek.pdf.

[8] Z. Karaca, "Relationship between the mechanical properties and the surface roughness of marble," International Journal of Materials Research, vol. 103, no. 5, pp. 633-637, 2012.

[9] M. Ersoy, L. Yeşilkaya, M. Y. Çelik, and Y. Geçer, "Investigation of the belt conveyor speed effect to the surface quality in marble polishing process," Journal of Polytechnic, vol. 17, no. 4, pp. 153160, 2014.

[10] G. E. Box and K. B. Wilson, "On the experimental attainment of optimum conditions," Journal of the Royal Statistical Society. Series B. Methodological, vol. 13, pp. 1-45, 1951.

[11] NIST/SEMATECH e-Handbook of Statistical Methods, http:// www.itl.nist.gov/div898/handbook/10/06/2016. 

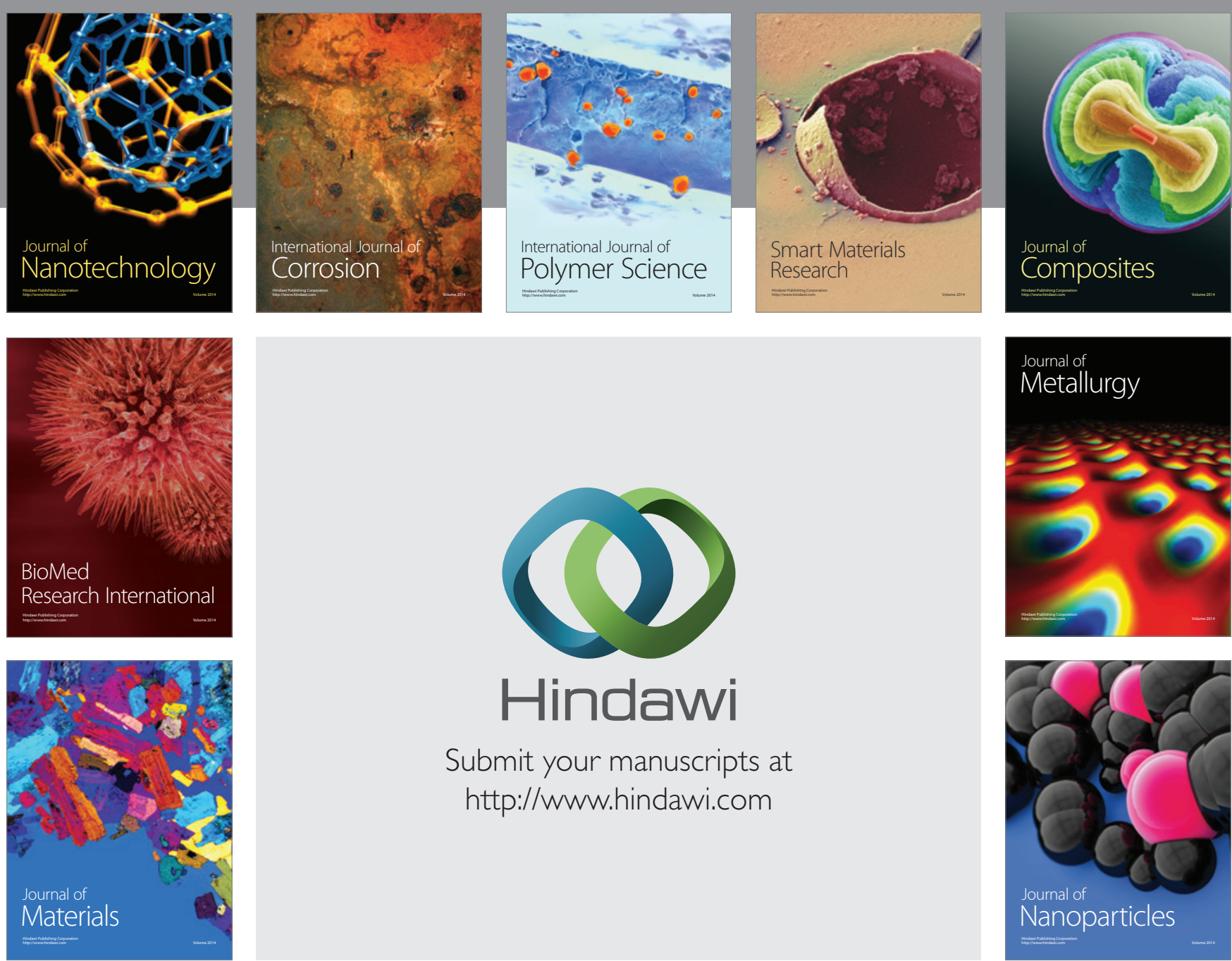

\section{Hindawi}

Submit your manuscripts at

http://www.hindawi.com



Materials Science and Engineering

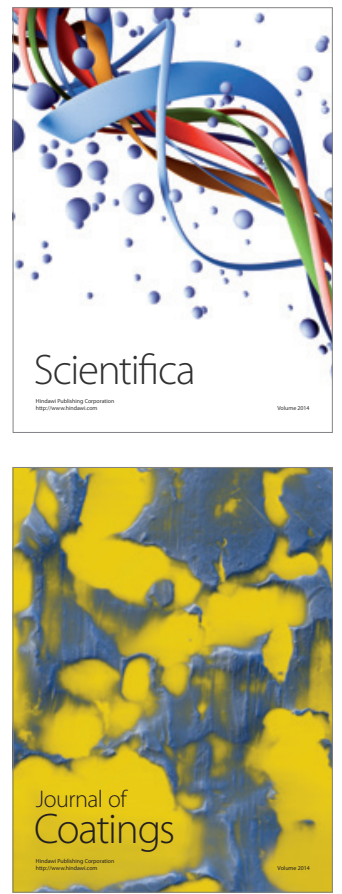


The Scientific World Journal
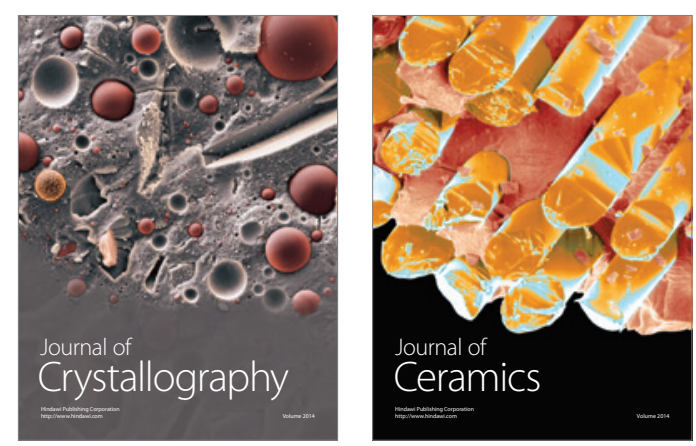
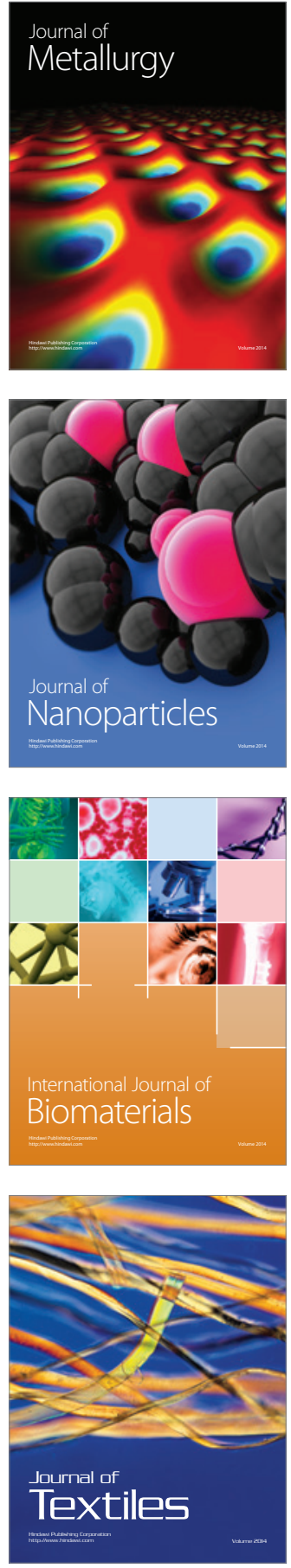